\title{
Mourning Glory
}




\section{CRITICAL AUTHORS \& ISSUES Josué Harari, Series Editor}

A complete list of books in the series is available from the publisher. 


\section{Mourning Glory The Will of the French Revolution}

\section{Marie-Hélène Huet}

\section{$\overline{\text { PENN }}$}

University of Pennsylvania Press

Philadelphia 
Copyright (C) 1997 University of Pennsylvania Press

All rights reserved

I0 98765432 I

Published by

University of Pennsylvania Press

Philadelphia, Pennsylvania I9I04

Library of Congress Cataloging-in-Publication Data

Huet, Marie Hélène.

Mourning glory : the will of the French Revolution /

Marie-Hélène Huet.

p. $\quad \mathrm{cm} .-$ (Critical authors $\&$ issues)

Includes bibliographical references and index.

ISBN 0-8122-34I4-6 (cloth : alk. paper). -

ISBN 0-8122-1617-2 (pbk. : alk. paper)

I. France-History-Revolution, 1789-I799. 2. Enlightenment-

France-Influence. 3. Robespierre, Maximilien, 1758-1794-

Philosophy. 4. Political science-Philosophy-History-r8th

century. 5. France-History-Reign of Terror, 1793-1794-Influence.

I. Title. II. Series.

DCI48.H84 1997

97-2936

944.04-dc2I

CIP 